\title{
LETTERS
}

\section{Turmeric editorial overreaches}

Some good general points are raised in the CMAJ editorial by Drs. Patrick and Stanbrook. ${ }^{1}$ However, their conclusion is much broader than what the linked research ${ }^{2}$ (on the use of curcumin in elective abdominal aortic aneurysm repair) supports.

Garg and colleagues ${ }^{2}$ examined a short duration (4 days) of intervention with curcumin perioperatively. Patrick and Stanbrook then cite the negative effect on a very specific surrogate marker (transient creatinine $)^{1}$ and fail to recognize that neither the duration of hospital stay nor clinical events were affected by use of curcumin. They concluded that the study by Garg and colleagues negates all the other studies that examined different aspects of turmeric and its compounds. Their conclusion is overreaching and simply not supported.

A flaw of the linked research is that the authors do not report on a critical factor that directly affects the measured outcome: the time of aortic clamping. Although this is routinely documented during the aortic aneurysm repair, by not acknowledging it in this study, any effect attributed to the studied intervention is questionable.

Below is a link to 2644 references regarding the effects of turmeric, subgrouped into 844 diseases: www. greenmedinfo.com/substance/turmeric. To say that the study by Garg and colleagues discounts each and every one of these is wrong on so many levels.

\section{Richard Beever MD CI}

Red Deer, Alta.

Cite as: CMAJ 2019 February 25;191:E239. doi: $10.1503 / \mathrm{cmaj} .71286$

\section{References}

1. Patrick K, Stanbrook MB. Take turmeric with a grain of salt. CMAJ 2018;190:E1270.

2. Garg AX, Devereaux PJ, Hill A, et al. Oral curcumin in elective abdominal aortic aneurysm repair: a multicentre randomized controlled trial. CMAJ 2018;190:E1273-80.

Competing interests: None declared. 